\title{
Discussion on Training of Automobile Marketing and Service Professionals
}

\author{
Wei Zhou \\ Beihai Vocational College \\ Beihai, China 536000
}

\author{
Shizeng Li \\ Guangxi Technological College of Machinery and \\ Electricity \\ Nanning, China 530007
}

\author{
Zhiyong Feng \\ Guangxi Technological College of Machinery and \\ Electricity \\ Nanning, China 530007
}

\begin{abstract}
Through the research on Guangxi automobile aftermarket and understanding of the demand for professional talents skilled at automotive marketing and service in the car aftermarket, the author gives the analysis of the existing problems in the vocational schools' training for professional talents of automobile sales and service and accurately position talents training for automotive marketing and service guided by the market demand in order to develop a high-quality, highskilled professionals who meet the needs of the automotive aftermarket.
\end{abstract}

Keywords-higher vocational education; technical service; marketing; talent training

\section{INTRODUCTION}

In recent years, the automobile industry in China has developed rapidly. Since 2004, China's car ownership has been growing at a rate of about $15 \%$, and China has become the most growing car consumer market in the world. With the continuous improvement of the living standards of the people, cars have become the necessary consumer goods in our daily life. The automotive aftermarket is expanding and technical service scope, including automotive marketing, automobile maintenance, automobile insurance claims, second-hand car trading and so on, is also experiencing growth, which demand greater for professional automotive marketing and service talents. How to accurately position the talent training of higher vocational colleges in automobile marketing and service, establish a reasonable talent cultivation system, highlight the practicality and professionalism of higher vocational education, and cultivate high-quality and high-skilled talents that meet the needs of the automotive aftermarket is of great significance.

\section{THE STATUS QUO OF DEMAND FOR TALENTS IN} AUTOMOTIVE MARKETING AND SERVICE PROFESSIONALS

\section{A. Demand for Talents of Automotive Marketing and Service Professionals}

"The statistical bulletin of 2016 national economic and social development of People's Republic of China "shows: The country's total automobile production reached $28,118,800$, an increase of $14.5 \%$, which exceeded one quarter of the world's total automobile production (global vehicle production reached 94.876 million); at the end of 2016, the country's total civilian vehicle ownership was 19.44 million, an increase of $12.8 \%$ from the end of the previous year, of which the number of private cars was 165.59 million, an increase of $15.0 \%$, and the number of civilian sedans was 108.76 million, an increase of $14.4 \%$, of which 10.152 million were private cars, an increase of $15.5 \%$.[1]. With the rapid development of China automobile industry, Guangxi automobile industry is not resigned to playing second fiddle and "statistical bulletin of 2016 national economic and social development of Guangxi Zhuang Autonomous Region" shows: The annual output of Guangxi Automobile exceeded the 2.4 million mark; at the end of 2016 , the number of civilian vehicles in the district was $4,273,400$, an increase of $16.6 \%$ over the previous year, of which passenger cars were 2,087,600, an increase of $18.2 \%$, and private car ownership was $3,781,200$, an increase of $19.4 \%$.[2]. The increase in vehicle output and inventory has led to a boom in the aftermarket, including car sales and after-sales service. At present, there are nearly 45000 authorized dealers in the country; there are more than 700 large car trading markets, and more than 4 million people are directly engaged in automobile marketing services; in addition, there are more than 800 large auto parts and automotive products market in China, with more than 700 used car markets and more than 3 million employees; the number of people who engage in automobile after-sales service (including automobile beauty and decoration, automobile insurance, automobile information consultation, car rental and other relevant fields) reach more than one million...Such a huge aftermarket for automotive marketing and after-sales service also means that the demand for automotive marketing and service professionals is increasing. According to statistics from the National Talent Network, the demand for automotive marketing and service professionals has entered the top five in overall social needs, and has become one of the four major professionals in the country's shortage of talent. 


\section{B. Requirements for Abilities of Professional Talents in Automotive Marketing and Service}

1) The professional post marketing and service profession should be qualified for: The automobile marketing service enterprise is the main direction of the auto marketing and service profession. Through the investigation of many automotive Sales Service Co in Guangxi area, including Nanning area, Liuzhou area, Guilin area, Beihai area and Baise area, the results show that the jobs that automobile marketing and service professionals are able to do are: car sales, car credit transactions, second-hand car assessment and transactions, auto parts sales, auto insurance and claims, etc. According to the specific circumstances of each auto sales service company, the positions can be further refined into more specific positions, such as auto sales consultants, front desks, auto insurance and claims specialists, auto after-sales service consultants, customer service specialists, showroom communicators, and auto sales representatives etc.

2) Requirements for ability of professional talents in automotive marketing and service:Through the investigation of the post-auto market in Guangxi, it is found that the ability requirements of automotive after-sales service-related companies for auto marketing and service professionals are concentrated in several aspects, such as social activity ability, professional skills, execution ability, and academic title requirements. Among them, social activities-related ability requires that employees have good auto market research capabilities, interpersonal communication skills, teamwork spirit, customer service awareness, and organizational and coordination capabilities; in terms of professional skills, employees are required to possess proficient computer operation skills, automotive construction knowledge and automotive technology evaluation capabilities, basic principles of automobile sales and sales skills, familiarity with automotive after-sales service procedures, car underwriting investigation and claims, new technology learning and Selfimproving ability; in terms of implementation capabilities, employees are required to have good work plan development capabilities, automotive sales planning and organization and implementation capabilities, car sales enterprise management and customer relationship management capabilities; In respect of academic qualifications, the opinions of auto after-sales service companies are relatively uniform; all employees are expected to have a college degree or above, have certain plasticity and increase their potential; the after-sales service companies of autos do not require high professional technical titles, and they pay more attention to professional qualifications and skills of employees.

In addition, during the investigation, it was discovered that although there are some differences in the quality requirements of employees in various aspects of different companies, all automotive after-sales service companies require that car marketing and service personnel should have good professional ethics, love and professional dedication, the spirit of solidarity and cooperation and the concept of observing laws and regulations, which show that modern companies pay more and more attention to the humanistic qualities of employees and the recognition and dedication of employees to the company.

\section{Status QuO OF TALENT TRAINING FOR AUTOMOBILE MARKETING AND SERVICE PROFESSIONALS}

\section{A. The Training Target and Positioning of Automotive Marketing and Service Professionals Are not Clear}

The automotive marketing and service profession in higher vocational education is not only related to the field of automotive technology services, but also involves the field of marketing. It is a cross-discipline, requiring students to not only have relatively solid automotive-related theoretical knowledge, but also have marketing skills and abilities. The occupational groups corresponding to the major are mainly automotive marketing and automobile after-sales service reception. Automobile sales can also be refined into automobile vehicle sales, automobile consumer credit, auto parts marketing, automobile insurance and claims, and evaluation and identification of used cars etc. However, at present, the training objectives and location of automobile technology service and marketing major in some vocational colleges are vague and professional posts are not clear. Moreover, graduates' core competencies are not well cultivated, and employment competitiveness is not enough.

\section{B. The Training Mode and Curriculum System of Automobile Marketing and Service Professionals Is not Reasonable}

The main purpose of higher vocational education is to cultivate high-quality skilled personnel in line with the needs of the enterprises, and to serve the first line of production. The higher vocational talent cultivation in Colleges and universities, should carry on the accurate positioning of the professional occupation and according to the characteristics of the corresponding professional positions, students shall be trained in the aspects of professional theory knowledge, practical ability and occupation quality so as to highlighting the practicality and occupation of higher vocational education , reflect the employment orient of talent cultivation and establish talent cultivation model of the combination of theory and practice. At present, many vocational colleges are not very rational in formulating the talent training program for the automotive marketing and service professional. The establishment of professional curriculum system is not reasonable, and even some individual colleges simply increase some marketing courses based on the professional courses of automobile inspection and maintenance technology., ignoring the cultivation of students' core career abilities; Secondly, the proportion of professional theoretical courses and practical courses is seriously out of balance; it over emphasizes the systematic nature of theoretical knowledge and neglects the training of practical ability; in addition, the teaching content of professional courses is inconsistent with the status quo of the enterprise with outdated knowledge, lack of new technology injection, and severe separation from the social reality, failing meet the needs of modern higher vocational education. 


\section{TRAINING REFORM OF AUTOMOBILE MARKETING AND SERVICE PROFESSIONALS}

\section{A. Determine the Training Objectives and Positioning of Automotive Marketing and Service Professionals}

The cultivation of talents in higher vocational colleges should be guided by the needs of the society (market) and clarify the objectives and positioning of professional talents training based on the principle of "what talents in society are needed are what talents we train". Meanwhile, the cultivation of core competences in students' posts should be emphasized [3] and send qualified skilled professionals for the community .According to the results of the investigation of the auto aftermarket in Guangxi, it can be seen that the vocational positions corresponding to graduates of vocational marketing and service majors are mainly concentrated in the sales of auto vehicles, auto credit transactions, auto insurance and claims, used car valuation transactions, and auto parts sales and automotive after-sales service reception. Therefore, the training objectives of the automotive marketing and service professionals should be positioned on the two sales groups of auto sales consultants and auto after-sales service consultants, and for these two professional posts, the professional talent training model and a reasonable professional curriculum system should be established .What's more, it's necessary to cultivate the core competencies of the students' posts to meet the needs of the company's professional positions.

\section{B. Establish the Training Mode of Automobile Marketing and Service Professionals and Reform the Professional Curriculum System}

Through extensive research on relevant enterprises in the automotive aftermarket in Guangxi region, we understand the development trend of the automotive industry and the requirements of companies for professional automotive technology service and marketing professionals. We have clarified the orientation of personnel training in this field and created the talent training model of "alteration of engineering and learning, and training of orders". Based on the requirements for professional talents of automobile-related companies, industry and company standards are introduced and the company produces professional competence standards and professional standards for human resources of auto sales and after-sales service jobs together with companies. Besides that, according to professional competence standards and professional norms, curriculum system of the school-enterprise cooperation based on typical work processes should be built; in the selection of teaching content, according to the actual needs of the enterprise, the professional courses and contents are set up and adjusted flexibly; in teaching methods, we combine classroom teaching, on-site teaching, and situational teaching to establish a modern vocational education concept of "alteration of working and learning", strengthen practical training, understand the processes, become familiar with practice, and master skills so that students can understand professional processes stereoscopically. The theoretical knowledge of learning is applied directly to practical work and the zero-distance interface between the teaching process and the professional process is realized [4].

\section{Strengthen Students' Professional Qualities}

The professional automotive marketing and service professional involves two areas of automotive technology service and marketing, covering two aspects of engineering technology and social humanities. It belongs to a crossdisciplinary discipline and mainly trains the skilled talents that engage in automotive marketing and develops automotive technology services. The graduates of this major must not only have a solid basic knowledge of automotive products and technologies, automotive marketing theory and marketing skills, but also have the professional qualities of "understanding technology, being capable of doing things, being good management, and doing well in services". Therefore, in the process of cultivating professionals, we must not only pay attention to the development of students' basic skills in car sales and technical services, but also strengthen the cultivation of students' professional qualities so that graduates can have good professional ethics and business mentality. The high-quality skilled talents with solid professional skills, good professional ethics, and a spirit of cooperative innovation shall be cultivated for society development.

\section{CONCLUSION}

Higher vocational colleges' automotive marketing and service professional undertakes the responsibility of training skilled craftsmen-type technical personnel for the automotive aftermarket. Therefore, in the training of professionals, we should be guided by market demand, analyze and study the needs and requirements for talents in the automotive aftermarket; define the orientation of professional personnel training; innovate professional personnel training models; construct a curriculum system based on typical work processes; reform curriculum content and teaching methods; strengthen the cultivation of students' professional qualities, and provide high-quality skilled talents for the society.

\section{REFERENCES}

[1] National Bureau of Statistics, "Statistical bulletin on national economic and social development 2016", 2016.

[2] Statistics Bureau of the Guangxi Zhuang Autonomous Region, "Statistical bulletin on national economic and social development of the Guangxi Zhuang Autonomous Region, 2016", 2016.

[3] Qun Qin, “An elementary introduction to the training of automotive electronic technology professionals" J, Guangxi Education”, 2013, 5: 68-69.

[4] Shizeng Li, "An elementary introduction on the training orientation and teaching reform of automobile plastic technology specialty" J, Quality Education Research of China,2011, 09:47-49. 